\title{
Knowledge, attitudes and practices related to self- medication with antimicrobials in Lilongwe, Malawi
}

\section{Cecilia S. Sambakunsi ${ }^{1,2}$, Lars Småbrekke ${ }^{3}$, Christine A. Varga ${ }^{2}$, Vernon Solomon ${ }^{2}$, John S. Mponda ${ }^{4}$}

1. Pharmacy Medicines and Poisons Board, Lilongwe 3, Malawi

2. College of Health Sciences, University of KwaZulu Natal, Durban, South Africa

3. Department of Pharmacy UIT - The Arctic University of Norway, Tromso, Norway

4. Department of Pharmacy, College of Medicine, Blantyre, Malawi

\section{Background}

\section{Abstract}

The use of antimicrobials is associated with the emergence of antimicrobial resistance (AMR), and self-medication increases the risk of the inappropriate use of antimicrobials. This study aims to describe the knowledge, attitudes, and practices (KAP) regarding selfmedication with antimicrobials among residents in Lilongwe, Malawi.

Methodology

This study has a cross-sectional, mixed-methods design. We conducted two focus group discussions ( $\mathrm{n}=15)$ to describe community attitudes towards self-medication with antimicrobials and used a structured questionnaire to collect data on individual KAP regarding self-medication from 105 respondents.

Results

Self-medication was common, and the sources of these medicines were market vendors, pharmacies, drugs shared with friends and family and those leftover from previous treatments. The lack of medical supplies, long distances to health facilities, poor attitudes of medical professionals towards patients, and past experience with the disease and treatment are the main factors that influence selfmedication. KAP respondents had little knowledge of antimicrobials, their use, or any awareness of AMR. Seventy-four per cent (n=78) were unable to differentiate antimicrobials from other categories of medicines, and $92.4 \%$ wrongly responded that antimicrobials could be used to stop a fever. Concerning attitudes towards self-medication, over 54\% wrongly believe that antimicrobials are effective in treating common colds. In regard to practice, $53 \%$ reported that they would use antimicrobials to treat upper respiratory infections, and $41 \%$ agreed that they must complete antibiotic therapy even if they are improving. Logistic regression analysis found that stocking antimicrobials at home for future use significantly promotes self-medication whereas an awareness of AMR would reduce selfmedication.

\section{Conclusion}

Self-medication is a public health risk that needs to be addressed urgently. Findings from this study point to the need for multifaceted interventions.

\section{Introduction}

Antimicrobial resistance (AMR) is a health problem, and surveillance reports indicate a high prevalence of AMR in common pathogens ${ }^{1,2}$. In addition to a negative impact on treatment outcomes, AMR also negatively affects the individual and the local and global economy. By 2050, AMR will cause 10 million deaths annually and a reduction in the gross domestic product if left unchecked3. The majority of these deaths and economic losses will be in countries where there is a high burden of infectious diseases ${ }^{3,4}$.

Self-medication with antimicrobials is widely practised in both developed and developing countries ${ }^{5-7}$, and is more prevalent where these agents are easily accessed without a prescription ${ }^{6,8-10}$. Self-medication may facilitate the indiscriminate use of these agents, for example, in treatment therapies for minor and self-limiting conditions ${ }^{5,8,11}$.

In Africa, different studies have investigated factors associated with self-medication among different population groups ${ }^{6,12-14}$. However, studies in Europe have documented differences in these factors at both individual and country levels ${ }^{10,15}$. It is, therefore, important to describe the knowledge, attitudes, and practices (KAP) related to self-medication with antibiotic drugs among urban residents of Lilongwe, Malawi. This study draws on the Theory of Planned Behaviour (TPB) to discuss the possible associations between TPB factors and either intention to self-medicate with antimicrobials or actual self-medication with antimicrobials. This study should be seen as groundwork for future behavioural intervention studies on self-medication with antimicrobials.

\section{Material and methods}

\section{Study design}

This study has a cross-sectional, mixed-methods research design that uses both qualitative and quantitative data collection methods.

\section{Study subjects}

Participants were $\geq 18$ years, and able and willing to provide informed consent. We excluded all visiting residents and non-consenting adults.

\section{Sampling}

Sampling consisted of the selection of a residential urban area and households.

For the selection of residential area, we used populationweighted cluster random sampling, based on the list of Lilongwe urban population by area as the primary sampling frame. As a result, area 25 was selected from the list.

We used snowballing to sample participants for focus group discussions (FGD). FGDs of seven to eight people were 
conducted separately for men and women in Chichewa to describe community attitudes towards self-medication with antimicrobials.

We used random sampling of households for the KAP survey. A structured questionnaire was used to describe individual KAP regarding self-medication with antimicrobials. The estimated sample size for the interviews was calculated using a $95 \%$ confidence interval with a $10 \%$ margin of error, on an approximated population of $\geq 20,000$ and a selfmedication prevalence of $56 \% 16$. Using a Raosoft ${ }^{\circledR}$ sample size calculator, the minimum estimated sample size for the survey was 95 . We added 15 individuals to account for nonresponse or withdrawals, reaching a final sample of $\mathrm{N}=110$.

We divided the area into 30 virtual clusters using modified cluster-sampling and used GPS coordinates to define cluster boundaries. These coordinates were superimposed on a satellite map using Google Earth (version 7.1.5.1557). Households, defined by sharing food and residence, were sampled from these virtual clusters. On average, we interviewed 3.6 individuals from each cluster.

\section{Data collection}

The investigator (CS) conducted and tape-recorded the FGDs. The investigator used a list of questions and probes to guide the discussions. Data on KAP regarding selfmedication with antimicrobials was collected from one participant in each household. The items in this questionnaire originated from previously validated questionnaires of similar KAP studies around the world ${ }^{6,15,17,18}$. However, the questions were slightly modified to suit the local setting and assure comprehension.

The questionnaire was developed in English, translated to Chichewa, and then translated back to English to ensure that meaning was kept in the translation process. The tool was pretested on non-medical colleagues $(n=10)$ to evaluate acceptability, comprehension, usability, and feasibility. Necessary adjustments in the wording or phrasing of the questionnaire items were made. Section 1 of the questionnaire gathered data on socio-demographic characteristics. Section 2 gathered data on knowledge of antimicrobials, their use, side effects, and the concept of AMR. Section 3 gathered attitudes towards self-medication with antimicrobials. Finally, section 4 collected information on practices concerning antimicrobial use, sources of medicines used in self-medication, and dosage and duration.

\section{Ethics}

The Humanity and Social Sciences Research Ethics Committee of University of KwaZulu Natal and the College of Medicine Research Ethics Committee of College of Medicine gave ethical approval. All participants provided written informed consent. Focus group participants provided additional consent to record their discussions.

\section{Data analysis}

FGDs were recorded and transcribed verbatim. The qualitative data analysis was conducted through a process of five interconnected stages using a framework analysis as described by Ritchie \& Spencer ${ }^{19}$. This approach allows themes to be developed from the focus group guide and the participants' narratives. The quantitative data were recorded in Epi Info (version 7.1.5.2) and analysed in IBM SPSS Statistics (version 24). The responses were categorised as either correct or incorrect, ignoring the differences between 'strongly agree' and 'agree' and 'strongly disagree' and 'disagree' to simplify the presentation. In the knowledge section, a 'not sure' response was categorised as equivalent to providing an incorrect response. In the arbitrary scoring system, each correct response scored one point, and an incorrect response scored zero. We then constructed composite variables from each dimension in the knowledge section. The results from the composite variables were dichotomised as either good knowledge or poor knowledge. Statistical analysis for quantitative, categorical variables was done using Pearson's chi-square test. We used directed acyclic graphs to identify the status of the predictors in the statistical model (www.dagitty.net). We conducted a logistical regression with the dependent variable being self-medication in the past three months; $\mathrm{p}<0.05$ was considered significant.

\section{Results}

\section{FGDs}

We identified five categories originating from the focus group discussion guide and the participants' narratives: common diseases and their causes, healthcare-seeking behaviours, sources of the antimicrobials used in self-medication, factors influencing self-medication, and recommendations to promote health-seeking behaviours.

\section{Common diseases and their causes}

Focus group participants reported malaria, diarrhoea, cough, skin infections, and sexually transmitted infections (STIs) as common diseases in their community. For malaria and diarrhoea, both children and adults are affected equally, whereas skin and STIs mainly affect adults. Most participants had good knowledge of the possible causes of these diseases. For example, it was reported that the use of unhygienic water and food causes diarrhoea, and not sleeping under mosquito net puts one at risk for malaria.

\section{Healthcare-seeking behaviours}

Participants were asked about normal actions when they or a family member is sick. In both groups, participants expressed a preference for providing self-treatment at home as a 'first-aid' and only seeking professional care if the conditions are unresponsive. These self-treatments ranged from non-use of medicines, such as tepid sponging in fever and oral rehydration in diarrhoea, to the use of both herbal and pharmaceutical products. For pharmaceutical products, the categories used were painkillers and antimicrobials. We noted a difference in the choice of medicines used for malaria between men and women. Most men said they use lumefantrine-artemether (LA) whereas their female counterparts use Fansidar ${ }^{\circledR}$ (sulfadoxine/pyrimethamine) or quinine. Women acknowledged that the most effective treatment option for malaria is LA, but LA is expensive and unaffordable.

Other antimicrobials mentioned were chloramphenicol or Flagyl® (metronidazole) for diarrhoea, amoxicillin for coughs, and Bactrim ${ }^{\circledR}$ (trimethoprim/sulfamethoxazole) for coughs, fever, and malaria. All of these agents are prescription-only medicines in Malawi. However, there were different opinions on self-medication in children. Men reported that they would take a sick child to the hospital for proper treatment. On the other hand, women expressed positive attitudes towards self-treating children.

'The way I would handle a sick child and my illness is different. If I notice a child is sick, I take her to the hospital to be treated properly. 
She is a child, and as a parent, I cannot tell what she is suffering from because she cannot exactly state what is wrong' PM1.

For example, [if] a child is sick at night, we struggle to find help. So we would go and knock at [the] neighbour's to share any medicine they may have' PF7.

\section{Sources of the antimicrobials used in self-medication}

In both groups, participants said they usually buy antimicrobials for self-medication from either a shop (hawker), a drug store, or a pharmacy. Women reported that they also use leftovers from previous treatments.

'So, if we have some leftover medications in the house, we just give either Bactrim or amoxicillin for coughs, even without the doctor's instructions' PF2.

The women reported that people also obtain medicines from friends and family. Although they acknowledged that drug sharing might result in using expired medicines or medications not indicated for their illness, they reported that drug sharing offers some convenience. For example, due to some people's busy schedules, they share medicines with others.

Most people are busy with either their businesses or work. I will give an example about people who are on ARV [antiretroviral] treatment. One can say I will share my medicine. When you collect yours, you can replace mine' PF6.

It is true...We can obtain medicines from friends or family. For example...my neighbour is a nurse. Sometimes when I am sick...I just call her' PF4.

\section{Factors influencing self-medication}

The following emerged from both groups.

\section{Frequent stock-outs in public facilities}

The participants indicated that most people in their community do not bother seeking medical care from hospitals because they do not expect to get medical treatment. Rather, they are advised to buy medicines from retail pharmacies. They lose confidence in the healthcare system, and as a result, they prefer to source medicines on their own and practise self-medication.

We do not bother going to hospitals to stand in long queues. We just go to pharmacies where we can find medicines to buy' PM6.

\section{Experience with illness and treatment}

The participants described being very familiar with some conditions and showed confidence in their self-diagnosis and self-treatment.

As for coughs, even if we go to a hospital, we know they will prescribe Bactrim or amoxicillin... So, most of the time when a person has a cough we either give Table 1: Socio- demographic characteristics of the study participants amoxicillin or Bactrim'

PF2.

Long distances the hospital

The long

distance

seek care from hospitals resulted in some people taking medicines without medical consultation, only going

to $a$ is worsening. clinic if the condition is not responding to the treatment or

'Sometimes it may happen that you are sick, and the hospital is very far [away]... so some people... can advise the sick or their guardian to buy a certain medication' PM4.

\section{Poor reception by healthcare workers}

Participants from both groups, but most notably women, expressed that healthcare workers are rude. They shout and make patients wait for long hours. Some participants indicated that people are afraid and feel embarrassed, especially if they have an STI and are asked to bring their sexual partners for treatment. This encourages people to self-diagnose and buy medicines from drug stores or pharmacies.

\section{Lack of awareness about their condition}

Some participants discussed that some people are unaware of the severity of their conditions, and they perceive their illnesses as simple and not warranting medical consultation.

\section{Recommendations to promote bealth-seeking behaviour}

The participants suggested the following as possible interventions to promote health-seeking behaviour and rational medical treatment:

- Availability of necessary equipment, medical products, and staff in public facilities.

- Public campaigns to inform people about different conditions and the importance of accessing treatment from hospitals.

- Building more clinics near communities to reduce travel distances to access medical care.

- Healthcare workers need to change their attitudes towards patients.

\section{KAP survey}

Out of 110 people invited, 105 consented to participate in the survey; $60(57.1 \%)$ were female. Among the participants, $45.7 \%$ had a low education status, while $38.1 \%$ and $16.2 \%$ had attained secondary and third-level education, respectively. The socio-demographic characteristics of the respondents are summarised in Table 1.

\section{Knowledge about antimicrobials and awareness of AMR}

\section{Identification of antimicrobials}

Out of 11 medicines listed, $74.3 \%(n=78)$ of the respondents were unable to identify antimicrobials, scoring seven or less. It was noted that $84.8 \%$ were able to correctly identify that

\begin{tabular}{|c|c|c|c|c|c|c|c|}
\hline \multirow{2}{*}{\multicolumn{2}{|c|}{$\begin{array}{l}\text { Gender } \\
\text { Age group (Count) }\end{array}$}} & \multicolumn{3}{|c|}{ Females } & \multicolumn{3}{|c|}{ Males } \\
\hline & & $\leq 29$ & $30-39$ & $\geq 40$ & $\leq 29$ & $30-39$ & $\geq 40$ \\
\hline \multirow[t]{4}{*}{ Education } & Never & 1 & 2 & 1 & 1 & 1 & 0 \\
\hline & Primary & 14 & 7 & 6 & 6 & 6 & 3 \\
\hline & Secondary & 18 & 3 & 1 & 16 & 1 & 1 \\
\hline & Tertiary & 5 & 1 & 1 & 6 & 4 & 0 \\
\hline \multirow[t]{3}{*}{ Marital status } & Single & 14 & 1 & 2 & 18 & 2 & 0 \\
\hline & Married & 24 & 12 & 7 & 11 & 9 & 4 \\
\hline & Widowed & 0 & 0 & 0 & 0 & 1 & 0 \\
\hline
\end{tabular}


Table 2: Knowledge statements about antimicrobials in relation to gender

\begin{tabular}{|c|c|c|c|c|}
\hline \multirow[t]{2}{*}{ Statement } & \multicolumn{2}{|l|}{ Female } & \multicolumn{2}{|l|}{ Male } \\
\hline & $\begin{array}{l}\text { Correct } \\
\text { n (\%) }\end{array}$ & $\begin{array}{l}\text { Wrong } \\
n \\
(\%) \\
\end{array}$ & Correct (\%) & Wrong (\%) \\
\hline \multicolumn{5}{|l|}{ Identification of antimicrobials } \\
\hline Amoxicillin & $31(29.5)$ & $29(27.6)$ & $23(21.9)$ & $22(21.0)$ \\
\hline Vitamin B Complex & $6(5.7)$ & $54(51.5)$ & $6(5.7)$ & $39(37.1)$ \\
\hline Bactrim (Co-trimoxazole) & $32(30.5)$ & $28(26.7)$ & $29(27.6)$ & $16(15.2)$ \\
\hline Fansidar (Sulphadoxine-Pyrimethamine) & $18(17.1)$ & $42(40)$ & $17(16.2)$ & $28(26.7)$ \\
\hline Lumefantrine-Artemether & $22(21.0)$ & $38(36.2)$ & $20(19.0)$ & $25(23.8)$ \\
\hline Ibuprofen & $50(47.6)$ & $10(9.5)$ & $39(37.1)$ & $6(5.7)$ \\
\hline Chloramphenicol & $15(14.3)$ & $45(42.9)$ & $16(15.2)$ & $29(27.6)$ \\
\hline Doxycycline & $6(5.7)$ & $54(51.4)$ & $5(4.8)$ & $40(38.1)$ \\
\hline Erythromycin & $2(1.9)$ & $58(55.2)$ & $4(3.8)$ & $41(39.1)$ \\
\hline Quinine & $24(22.9)$ & $36(34.3)$ & $25(23.8)$ & $20(19.0)$ \\
\hline Flagyl (Metronidazole) & $30(28.6)$ & $30(28.6)$ & $25(23.8)$ & $20(19.0)$ \\
\hline \multicolumn{5}{|l|}{ Knowledge about the antimicrobial use } \\
\hline Antimicrobials kill germs & $9(8.6)$ & $51(48.6)$ & $11(10.5)$ & $34(32.4)$ \\
\hline Antimicrobials are used to stop fever & $6(5.7)$ & $54(51.4)$ & $2(1.9)$ & $43(41.0)$ \\
\hline Antimicrobials stop back pain & $10(9.5)$ & $50(47.6)$ & $1(1.0)$ & $44(41.9)$ \\
\hline You can stop antimicrobials when feeling better & $25(23.8)$ & $35(33.3)$ & $17(16.2)$ & $28(26.7)$ \\
\hline \multicolumn{5}{|l|}{ Awareness about AMR } \\
\hline $\begin{array}{l}\text { Future usefulness is reduced when you take antimicrobials } \\
\text { unnecessarily }\end{array}$ & $31(29.5)$ & $29(27.6)$ & $23(21.9)$ & $22(21.0)$ \\
\hline Resistant germs can affect other patients or me & $35(33.3)$ & $25(23.8)$ & $22(21.0)$ & $23(21.9)$ \\
\hline
\end{tabular}

\section{Table 3: Definition of antimicrobial resistance}

\begin{tabular}{|l|l|l|l|l|}
\hline \multirow{5}{*}{ AMR awareness } & \multicolumn{2}{|l|}{ Gender } & \multirow{2}{*}{ Total } \\
\cline { 3 - 5 } & & Female & Male & \\
\cline { 2 - 5 } & Government fighting & 22 & 8 & 30 \\
& counterfeit medicines & & & \\
\cline { 2 - 5 } & Treatment becoming ineffective & 18 & 27 & 45 \\
\cline { 2 - 5 } & Never heard of AMR & 20 & 10 & 30 \\
\hline Total & 60 & 45 & 105 \\
\hline
\end{tabular}

ibuprofen is not an antimicrobial. The next highest score was on Bactrim, where $58.1 \%$ correctly recognised it as an antimicrobial. However, only six people correctly identified erythromycin as an antimicrobial. There was no significant difference in antibiotic identification scores and gender (Table 2).+

\section{Awareness of $A M R$}

Forty-five participants $(42.9 \%)$ correctly responded that previous successful treatments become ineffective in AMR (Table 3). However, there was a higher proportion of correct responses to AMR statements compared to the antimicrobial use dimension. About 51\% agreed that the unnecessary use of antimicrobials would reduce their future usefulness. Furthermore, 54.3\% correctly stated that resistant bacteria could affect them and other patients. There was no significant gender difference in the level of knowledge about AMR.

\section{Attitudes concerning antimicrobial use}

In treating upper respiratory infections (URIs), 56 (53\%) participants reported that they would use antimicrobials to treat a common cold, whereas $10(9.5 \%)$ were unsure. Ninety participants $(85.7 \%)$ responded that their family members would take antimicrobials for a cough. Furthermore, the participants demonstrated ambivalent attitudes towards storage of antimicrobials in homes for future use and 
Table 4: Results of Logistic Regression analysis to predict self-medication

\begin{tabular}{|l|l|l|l|l|}
\hline Independent variable & $\begin{array}{l}\text { Unadjusted } \\
\text { Odds ratio (95\% C.I) }\end{array}$ & Significance & $\begin{array}{l}\text { Adjusted Odds } \\
\text { ratio (95\% C.I) }\end{array}$ & Significance \\
\hline $\begin{array}{l}\text { Knowledge of antibiotic } \\
\text { use }\end{array}$ & $0.918(0.602-1.401)$ & 0.693 & $0.863(0.472-1.578)$ & 0.632 \\
\hline $\begin{array}{l}\text { Knowledge of drug } \\
\text { identification }\end{array}$ & $0.961(0.827-1.116)$ & 0.601 & $0.842(0.669-1.059)$. & 0.142 \\
\hline $\begin{array}{l}\text { Awareness of } \\
\text { antimicrobial resistance }\end{array}$ & $0.360(0.161-0.803)$ & $0.013^{*}$ & $0.179(0.059-(0.544)$ & $0.002^{*}$ \\
\hline $\begin{array}{l}\text { Stocking } \\
\text { antimicrobials at home }\end{array}$ & $2.191(0.995-4.824)$ & 0.052 & $2.717(1.092-6.761)$ & $0.032^{*}$ \\
\hline $\begin{array}{l}\text { Taking medicines } \\
\text { as directed }\end{array}$ & $0.206(0.039-1.072)$ & 0.061 & $0.163(0.026-1.022)$ & 0.053 \\
\hline Age in years & $0.985(0.939-1.033)$ & 0.534 & $0.978(0.925-1.034)$ & 0.427 \\
\hline
\end{tabular}

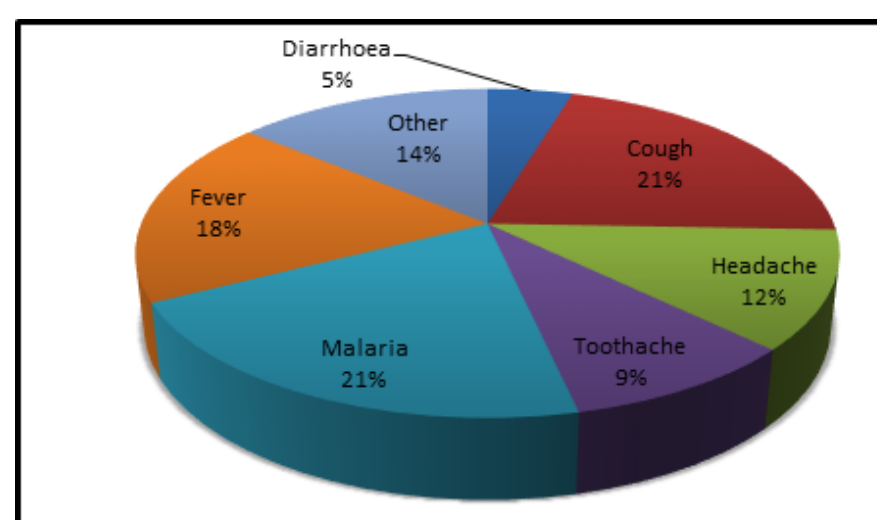

Figure 1: Indication for self-medication

compliance with treatment regimens. For example, 67.6\% of participants indicated that they keep antimicrobials in their homes for emergencies, while $92.4 \%$ reported that they take medications as directed by a medical professional, and $41 \%$ indicated that they would complete their antimicrobial treatments. There were no significant gender differences $(\mathrm{p}>0.05)$.

\section{Practices related to self-medication}

Self-medication was common. Forty-three respondents had practised self-medication in the three months before the study to treat malaria, cough, fever, or headache (Figure 1). Of these, 26 had used antimicrobials. The majority of these medicines were obtained from market vendors and pharmacies without a prescription, leftover from previous treatment, and shared with friends and family. The reasons for the self-medication were that the participants perceived the disease did not warrant a medical consultation, for emergency use, and the long travel distance to the hospital and they were dissatisfied with the medical care at the hospital and unavailability of medical supplies in public hospitals.

\section{Prediction of self-medication}

Based on the results from univariate analysis and directed acyclic graphs (DAG) models, we constructed a logistic regression model to predict the effects of age, knowledge of antimicrobial use, ability of drug identification, awareness about AMR, storage of antimicrobials at home, and taking medicines as directed. This model explained $24.4 \%$ of the variance in self-medication (Nagelkerke R2 $=0.244$ ). Awareness of being affected by AMR and stocking antimicrobials at home were significantly associated with self-medication. Knowledge of AMR predicted a reduction in self-medication, whereas people stocking antimicrobials at home were 2.7 times more likely to self-medicate. Also, the model predicted that always taking medicines as directed by the nurse or doctor reduces the probability of selfmedication. However, the association was not significant (Table 4).

\section{Discussion}

To the best of our knowledge, this is the first study using a mixed-methods design to describe KAP related to selfmedication with antimicrobial agents in a residential area of Lilongwe.

\section{Knowledge and attitudes towards self-medication with antibiotic medicines}

According to TPB, attitudes towards self-medication are formed after deliberate consideration of the available information ${ }^{20}$. Knowledge has an intrinsic relationship with attitudes, which precedes intention. Overall, the study population had low levels of knowledge regarding the effectiveness of antimicrobials and AMR. Few studies have investigated the extent of participants' recognition of antimicrobials, but the average recognition in our study is higher than those reported among Latinos (66\%) and Greeks $(27.5 \%)^{21,22}$. Several factors may lead to low levels of knowledge. In Malawi, the average dispensing time is too short to inform a patient about their medication adequately ${ }^{23}$, possibly contributing to the confusion our participants had in distinguishing antimicrobials from other categories of medicines. Inadequate knowledge about the importance of completing antimicrobial therapy and awareness of AMR has been reported in several studies, and it has been associated with indiscriminate use of antimicrobials among the general public $^{12,13,15,24,25}$.

Therefore, it is not surprising that our respondents also had incorrect attitudes towards self-medication. The extent of the use of antimicrobials in the management of URI in our 
study is comparable to the proportions reported in Kuwait and Nigeria $(57.1 \%-61 \%)^{12,26}$, but higher compared to Britain and Malaysia ${ }^{18,24}$. Indiscriminate use of antimicrobials may contribute to the selection of AMR, increased costs, and risk of adverse effects. Also, participants demonstrated ambivalent attitudes towards compliance and completion of antimicrobial therapy and this discrepancy suggests that individuals would follow instructions on dosing regimens but not treatment duration.

\section{Subjective norms}

Subjective norms are the social pressure associated with behaviour. The findings demonstrate that the respondents were influenced by their social contacts in obtaining medicines or information on self-medication. The practice of drug sharing has also been reported in several studies ${ }^{12,27-30}$. Drug sharing is worrisome from a public health perspective as it may result in people using the wrong treatment regimens and in sub-therapeutic doses. This may introduce selection pressure and the development of resistance. However, there is a need to investigate further the extent of this practice to develop targeted interventions to combat drug sharing.

\section{Perceived behaviour control}

Perceived behaviour control are factors that may facilitate or inhibit self-medication. The FGDs and KAP survey identified several hospital-system and people-related factors that might influence self-medication. The unreliable availability of medical supplies in public hospitals, inadequate healthcare infrastructure, and a shortage of trained staff can be categorised as hospital-related factors, whereas experience with illness and treatment, rude health professionals, and a lack of knowledge about disease conditions are peoplerelated factors. A few studies have demonstrated the possible effects of hospital-related factors on self-medication ${ }^{31}$. In Africa, drug stock-outs have been reported in public health systems, mainly due to weak procurement and supply chain management systems and inadequate financing ${ }^{32}$. Erratic medical supply, shortage of trained medical staff coupled with high levels of infectious diseases, high populations, and long waiting hours in hospitals hinder access to healthcare and promote self-medication.

Familiarity with disease condition and treatment may enhance people's perceptions of control. Our findings that self-medication with antimicrobials is influenced by previous experience with illness and treatment is consistent with other studies ${ }^{30,33,34}$. Focus group participants indicated that some medical staff are rude to patients, and they felt belittled by the lack of respect they experience. This behaviour is a barrier to healthcare utilisation and may promote self-medication. Our findings are in line with a study in Malawi reporting that rude healthcare workers were forcing pregnant women to seek maternal care from traditional birth attendants ${ }^{35}$. Findings from our study further suggest easy access to antimicrobials without a prescription from retail pharmacies and/or other informal sources such as vendors would make self-medication more practical.

\section{Self-medication practices}

The preference forself-treatmentconfirms anecdotal evidence suggesting that self-medication is a common practice. The prevalence of self-medication with antimicrobials in this study is comparable with levels found in Bangladesh (26.7\%) and Nigeria $(24 \%)^{9,11}$. Due to the resistance of malaria, both Fansidar and quinine are no longer the preferred treatment ${ }^{36}$
Men are usually more financially stable than women and hence can afford to buy the more expensive LA. In Malawi, just like most African countries, children spend more time with their mothers than fathers. This may explain why most women felt more confident at self-diagnosis and self-treating their children. Other studies have also reported higher self-medication rates of children by mothers ${ }^{37}$. However, a qualitative study among Latinos reported that both men and women were reluctant to practice self-medication on children ${ }^{33}$.

We noted that self-medication might result in the use of incorrect treatment. For example, it was reported that Bactrim is used in self-medication to treat malaria. Although Bactrim is structurally similar to Fansidar, its use in malaria is inappropriate. Regarding associations between demographic characteristics and either knowledge, attitudes, or practices regarding self-medication with antimicrobials, results differ between studies ${ }^{12,15,26}$. These variations may be due to cultural and/or setting differences. We found no significant associations between any of the demographic characteristics and either knowledge, attitudes, or practice.

\section{Prediction of self-medication with antimicrobials}

The logistic regression model has a self-medication status as the outcome variable whereas age in years, knowledge of antimicrobial use, knowledge of drug identification, awareness of AMR, storage of antimicrobials for future use, and taking medicines as directed are covariates. The adjusted odds ratios (ORs) showed modest changes compared to the univariate analysis, and the model explained $24.4 \%$ of the variance in self-medication. This indicates a mediocre performance of the model, possibly due to unmeasured confounders. However, it is expected as we have no information on the disease triggering the decision to selfmedicate. Similar to findings in Europe, knowledge about AMR is associated with reduced self-medication whereas stocking antimicrobials at home increases the probability of self-medication ${ }^{5}$.

This study has several limitations. Focus group participants were selected using snowball sampling to promote active participation in the discussions. However, this method of sampling may have reduced group variation as the participants may have had similar social networks. Also, this may have inhibited some participants in discussing issues they felt were socially embarrassing in front of their acquaintances. The KAP survey has a limited sample size $(\mathrm{n}=105)$, and unmeasured covariates are probably associated with selfmedication. This would have affected the performance of the statistical model. However, the choice of statistical model was guided by the use of DAGs, minimising the risk of bias. Also, this was a descriptive cross-sectional study. By the nature of cross-sectional studies, we cannot deduce causal relations. Lastly, these findings were reported by the participants and are dependent on their recall ability and honesty or lack thereof. These limitations may affect the generalisability of our findings.

\section{Conclusion}

The intention to self-medicate and actual self-medication is common. The respondents have inadequate knowledge about antimicrobial use and awareness of AMR and incorrect attitudes towards the effectiveness of antimicrobials in URIs. Furthermore, there are hospital-system and people-related factors that may also facilitate self-medication. The findings 
from this study highlight the need to further investigate factors that may influence self-medication using a larger sample size and a comparison of urban and rural settings.

\section{Acknowledgements}

We acknowledge the following individuals for their support towards the project: Prof. Sabiha Yusuf Essack, Dr Fanuel Lampiao, Dr Rajab Mkakosya, Kathy Murrell, Francis Sambakunsi, and Martin Msukwa.

\section{Funding}

This research was funded by a NORAD grant through the NORHED antibiotic stewardship and conservancy in Africa.

\section{References}

1.World Health Organization (WHO). Antimicrobial Resistance Global Report on Surveillance; 2014 [cited 2014 Nov 15]. Available from: https://www.who.int/drugresistance/documents/surveillancereport/en/.

2. WHO. Growing antibiotic resistance forces updates to recommended treatment for sexually transmitted infections. [press release]. Geneva, Switzerland; WHO: 30 August 2016.

3. O'Neill J. Antimicrobial Resistance: Tackling a Crisis for the Health and Wealth of Nations; 2014 [cited 2016 Oct 11]. Available from: http:// amr-review.org/sites/default/files/Report-52.15.pdf.

4. Okeke I, Laxminarayan R, Bhutta Z. Antimicrobial resistance in developing countries. Part I: recent trends and current status. Lancet Infect. 2005;5:481-93. doi:10.1016/S1473-3099(05)70189-4.

5. Grigoryan L, Haaijer-Ruskamp FM, Burgerhof JGM, et al. Selfmedication with antimicrobial drugs in Europe. Emerg Infect Dis. 2006;12:452-9. doi:10.3201/eid1203.050992.

6. Awad A, Eltayeb I, Matowe L, Thalib L. Self-medication with antibiotics and antimalarials in the community of Khartoum State, Sudan. J Pharm Sci. 2005;8:326-31. doi:10.5455/pmb.1314892446.

7. Mainous AG III, Cheng AY, Garr RC, Tilley BC, Everett CJ, McKee MD. Nonprescribed antimicrobial drugs in Latino community, South Carolina. Emerg Infect Dis. 2005;11(6):883-8. doi:10.3201/ eid1106.040960.

8. Berzanskyte A, Valinteliene R, Haaijer-Ruskamp FM, Gurevicius R, Grigoryan L. Self-medication with antibiotics in Lithuania. Int J Occup Med Environ Health. 2006;19(4):246-53.

9. Biswas M, Roy MN, Manik MIN et al. Self-medicated antibiotics in Bangladesh: a cross-sectional health survey conducted in the Rajshahi City. BMC Public Health. 2014;14:847. doi:10.1186/1471-2458-14847.

10. Grigoryan L, Burgerhof JGM, Degener JE et al. Determinants of self-medication with antibiotics in Europe: the impact of beliefs, country wealth and the healthcare system. J Antimicrob Chemother. 2008;61(5):1172-9. doi:10.1093/jac/dkn054.

11. Sapkota AR, Coker ME, Rosenberg Goldstein RE et al. Selfmedication with antibiotics for the treatment of menstrual symptoms in Southwest Nigeria: a cross-sectional study. BMC Public Health. 2010;10:610. doi:10.1186/1471-2458-10-610.

12. Auta A, Banwat SB, David S, Dangiwa DA, Ogbole E, TorAnyiin AJ. Antibiotic use in some Nigerian communities: knowledge and attitudes of consumers. Trop J Pharm Res. 2013;12:1087-92. doi:10.4314/tjpr.v12i6.33.

13. Donkor ES, Tetteh-Quarcoo PB, Nartey P, Agyeman IO. Selfmedication practices with antibiotics among tertiary level students in Accra, Ghana: a cross-sectional study. Int J Environ Res Public Health. 2012;9:3519-29. doi:10.3390/ijerph9103519.

14. Bello F, Olayemi O, Morhason-Bello I, Adekunle A. Patterns and predictors of self-medication amongst antenatal clients in Ibadan, Nigeria. Niger Med J. 2011;52:153. doi:10.4103/0300-1652.86124.
15. Grigoryan L, Burgerhof JGM, Degener JE et al. Attitudes, beliefs and knowledge concerning antibiotic use and self-medication: a comparative European study. Pharmacoepidemiol Drug Saf. 2007;16:1234-43. doi:10.1002/pds. 1479 .

16. Novignon J, Mussa R, Msonda T, Nonvignon J. The use of non-prescription medicine versus self-assessed health: evidence from Malawi. Int Arch Med. 2011;4(1):38. doi:10.1186/1755-7682-4-38.

17. Vanden Eng J, Marcus R, Hadler JL et al. Consumer attitudes and use of antibiotics. Emerg Infect Dis. 2003;9(9):1128-35. doi:10.3201/ eid0909.020591.

18. McNulty C, Boyle P, Nichols T et al. Don't wear me out-the public's knowledge of and attitudes to antibiotic use. J Antimicrob Chemother. 2007;59(4):727-38. doi:10.1093/jac/dk1558.

19. Ritchie J, Spencer L. Qualitative data analysis for applied policy research. In: Huberman A, Miles MB, editors. The qualitative researcher's companion. London: Sage; 2002. p. 305-30.

20. Conner M, Norman P, editors. Predicting health behaviour. 2nd ed. Berkshire: Open University Press; 2005.

21. Landers TF, Ferng Y-H, McLoughlin JW, Barrett AE, Larson E. Antibiotic identification, use, and self-medication for respiratory illnesses among urban Latinos. J Am Acad Nurse Pract. 2010;22(9):48895. doi:10.1111/j.1745-7599.2010.00539.x.

22. Rousounidis A, Papaevangelou V, Hadjipanayis A, et al. Descriptive study on parents' knowledge, attitudes, and practices on antibiotic use and misuse in children with upper respiratory tract infections in Cyprus. Int J Environ Res Public Health. 2011;8:3246-62. doi:10.3390/ ijerph8083246.

23. Awad AI, Himad HA. Drug-use practices in teaching hospitals of Khartoum State, Sudan. Eur J Clin Pharmacol. 2006;62(12):1087-93. doi:10.1007/s00228-006-0216-x.

24. Ling Oh A, Hassali MA, Al-haddad MS, et al. Public knowledge and attitudes towards antibiotic usage: a cross-sectional study among the general public in the state of Penang, Malaysia. J Infect Dev Ctries. 2011;5(5):338-47.

25. Napolitano F, Izzo MT, Di Giuseppe G, Angelillo IF. Public knowledge, attitudes, and experience regarding the use of antibiotics in Italy. PLoS One. 2013;8(12):e84177. doi:10.1371/journal. pone. 0084177 .

26. Awad AI, Aboud EA. Knowledge, attitude and practice towards antibiotic use among the public in Kuwait. PLoS One. 2015; 10:e0117910. doi:10.1371/journal.pone.0117910.

27. Ali SE, Ibrahim MIM, Palaian S. Medication storage and self-medication behaviour amongst female students in Malaysia. Pharm Pract (Granada). 2010;8(4):226-32. doi:10.4321/S188636552010000400004 .

28. Temu-Justin M, Risha P, Mlavwasi Y, Makwaya C, Leshabari MT. Availability and usage of drugs at household level in Tanzania: case study in Kinondoni district, Dar es Salaam. East Cent African J Pharm Sci. 2002;5:49-54. doi:10.4314/ecajps.v5i3.9688.

29. Ocan M, Obuku EA, Bwanga F et al. Household antimicrobial selfmedication: a systematic review and meta-analysis of the burden, risk factors, and outcomes in developing countries. BMC Public Health. 2015;15(1):742. doi:10.1186/s12889-015-2109-3.

30. Ocan M, Bwanga F, Bbosa GS et al. Patterns and predictors of self-medication in Northern Uganda. PLoS One. 2014;9(3):1-7. doi:10.1371/journal.pone.0092323.

31. Radyowijati A, Haak H. Improving antibiotic use in low-income countries: an overview of evidence on determinants. Soc Sci Med. 2003;57(4):733-44. doi:10.1016/S0277-9536(02)00422-7.

32. Quick JD, Boohene N-A, Rankin J, Mbwasi RJ. Medicines supply in Africa. BMJ. 2005;331(7519):709-10. doi:10.1136/bmj.331.7519.709.

33. Smainous AG, Diaz V A, Carnemolla M. Factors affecting Latino https://dx.doi.org/10.4314/mmj.v31i4.2 
adults' use of antibiotics for self-medication. J Am Board Fam Med. 2008;21(2):128-34. doi:10.3122/jabfm.2008.02.070149.

34. Afolabi AO. Factors influencing the pattern of self-medication in an adult Nigerian population. Ann Afr Med. 2008;7(3):120-7.

35. Kambala C, Morse T, Masangwi S, Mitunda P. Barriers to maternal health service use in Chikhwawa, Southern Malawi. Malawi Med J. 2011;23(1):1-5. doi:10.4314/mmj.v23i1.67673.
36. National malaria control programme. Government of Malawi Ministry of Health Revised Guide for the Management of Malaria. 2011.

37. Nguyen K Van, Thi Do NT, Chandna A, et al. Antibiotic use and resistance in emerging economies: a situation analysis for Viet Nam. BMC Public Health. 2013; 13:1158. doi:10.1186/1471-2458-13-1158. 